Diagnostic Accuracy Report

\title{
Comparative Evaluation of the Accuracy of Immunoassay with Liquid Chromatography Tandem Mass Spectrometry (LC/MS/MS) of Urine Drug Testing (UDT) Opioids and Illicit Drugs in Chronic Pain Patients
}

Laxmaiah Manchikanti, MD, Yogesh Malla, MD, Bradley W. Wargo, DO, and Bert Fellows, MA

From: Pain Management Center of Paducah, Paducah, KY.

Dr. Manchikanti is Medical Director of the Pain Management

Center of Paducah, Paducah, $\mathrm{KY}$, and Associate Clinical Professor, Anesthesiology and Perioperative Medicine, University of Louisville, Louisville, KY

Dr. Malla is an Interventional

Pain Physician at the Pain Management Center of Paducah, Paducah, KY

Dr. Wargo is an Interventional

Pain Physician at the Pain Management Center of Paducah, Paducah, KY

Bert Fellows is Director Emeritus of Psychological Services at the Pain Management Center of Paducah, Paducah, KY.

Address correspondence: Laxmaiah Manchikanti, M.D. 2831 Lone Oak Road

Paducah, Kentucky 42003 E-mail: drlm@thepainmd.com

Detailed disclosure information is available on page 183 .

Manuscript received: $02 / 25 / 2011$ Accepted for publication: 03/04/2011

Free full manuscript: www.painphysicianjournal.com
Background: The challenge for physicians in treating chronic pain with opioids is to eliminate or significantly curtail abuse of controlled prescription drugs while assuring proper treatment when indicated. Urine drug testing (UDT) has been shown to be a useful approach in identifying patterns of compliance, misuse, and abuse. However, significant controversy surrounds the diagnostic accuracy of UDT performed in the office (immunoassay) and the requirement for laboratory confirmation with liquid chromatography tandem mass spectrometry (LC/MS/MS).

Study Design: A diagnostic accuracy study of urine drug testing.

Study Setting: The study was performed in an interventional pain management practice, a tertiary referral center, in the United States.

Objective: The objective of this study was to compare the results of UDT of immunoassay inoffice testing (index test) to LC/MS/MS (reference test).

Methods: One-thousand participants were recruited from an interventional pain management program. Urine sample was collected from all the consecutive patients with demographic information. Immunoassay testing was performed by a nurse at the location, laboratory assessment was performed with LC/MS/MS

Results of the index test were compared to the reference test in all patients. The sensitivity, specificity, false-positive, and false-negative rates, and index test efficiency (agreement) were calculated.

Results: Overall, results showed that confirmation was required in $32.9 \%$ of the specimens. Agreement for prescribed opioids was high with the index test (80.4\%). The reference test of opioids improved the accuracy by $8.9 \%$ from $80.4 \%$ to $89.3 \%$. Non-prescribed opioids were used by $5.3 \%$ of patients. The index test provided false-positive results for non-opioid use in $44 \%$ or 83 of 120 patients.

For illicit drugs, the false-positive rate by index test was $0 \%$ for cocaine, whereas it was $2 \%$ for marijuana, $0.9 \%$ for amphetamines, and $1.2 \%$ for methamphetamines.

Limitations: The limitations include a single site study utilizing a single POC kit and a single laboratory, as well as technical sponsorship.

Conclusion: The UDT with immunoassay in an office setting is appropriate, convenient, and cost-effective. Compared with laboratory testing for opioids and illicit drugs, immunoassay inoffice testing had high specificity and agreement, demonstrating the value of immunoassay drug testing. Because of variable sensitivity, clinicians would be well-advised to take a cautious approach when interpreting the results.

Key words: Controlled substances, opioids, illicit drugs, abuse, liquid chromatography tandem mass spectrometry, immunoassay, urine drug testing

CLINICAL TRIAL: NCT01052155

Pain Physician 2011; 14:175-187 
The treatment of chronic pain, escalating therapeutic opioid use and abuse, and the non-medical use of prescription drugs have been topics of intense focus and debate (1-7). The present state of affairs is based on prescriptions for chronic non-cancer pain; subjective complaints of pain; recommendations from federal, state, and local governments; professional associations; massive sales promotion activities from the pharmaceutical companies; accreditation agencies; physicians promoting opioid therapy; and finally the public-at-large expecting pain relief at any cost, rather than scientific data on efficacy and safety (1,5-9). Similar states of affairs have been described in other countries including Denmark (9). However, Americans, constituting only $4.6 \%$ of the world's population, have been consuming $80 \%$ of the global opioid supply, and $99 \%$ of the global hydrocodone supply, in addition to two-thirds of the world's illegal drugs $(1,2,6,7,10,11)$.

Retail sales of some commonly used opioid medications have increased significantly, with an increase of $866 \%$ for oxycodone and 1,293\% for methadone, whereas average sales of opioids per person have increased 402\% from 1997 to 2007 (1). In addition, surveys of non-prescription drug abuse (12), emergency department visits involving prescription-controlled drugs (13), unintentional deaths due to prescription controlled substances $(5,14-17)$, therapeutic use of opioids $(1,9,18$ 23), lack of improvement or deterioration in functional status $(9,21,24-29)$, adverse effects $(24-27,30)$, and opioid abuse (1-5,31-33) illustrate grave statistics. At the same time, chronic pain's prevalence and its associated disability continue to increase $(34,35)$, while the scientific evidence for the effectiveness of opioids for chronic non-cancer pain remains unclear $(5,24-27)$.

The challenge is to eliminate or significantly curtail abuse of controlled prescription drugs while still assuring the proper treatment of those patients with evident indications. Adherence monitoring, including urine drug testing (UDT), has been shown to be a useful approach to assist in identifying and/or predicting patterns of drug use, compliance, misuse, and abuse (36). UDT provides relatively good specificity, sensitivity, ease of administration, and cost (36). However, controversies also exist regarding the clinical value of UDT, partly because most current methods are designed for, or adapted from, forensic or occupational deterrent-based testing for illicit drug use and are not entirely optimal for application in chronic pain management settings. Further, additional issues also exist related to excessive use, misuse, abuse, and financial incentives (36-45). UDT is performed to de- tect the presence of prescribed medications (i.e., compliance testing) and to identify substances that are not expected to be present in the urine, such as non-prescription or illicit drugs (i.e., forensic testing). The most commonly used Current Procedural Terminology (CPT) codes for UDT, 80101 and 80102, showed 343\% and 364\% increases from 2004 to 2007 and an increase in allowed charges of $452 \%$ and $387 \%$; the total allowed charges exceeded $\$ 50$ million in 2007.45 The abuses related to the utilization of UDT, its value and validity, and exploding costs, led the Centers for Medicare and Medicaid (CMS) administration to impose new regulations for UDT reimbursement (37-45).

Debate surrounds the validity of in-office UDT of chronic pain patients by immunoassay methodology that has not been validated with liquid chromatography tandem mass spectrometry (LC/MS/MS). Due to multiple methodological issues, an in-office immunoassay confirmed by an independent laboratory is commonly regarded as the best and most sensitive UDT, but at the expense of escalating costs. Other issues involved are the knowledge of the physician who interprets the drug screening (including having knowledge about opioid metabolites), appropriate testing methods in an office setting, and the cost involved $(37,40,41,45)$.

UDT manufacturers focus their marketing efforts on the value and validity of laboratory testing, and are supported by physicians who derive significant income from these tests $(37,44,46,47)$. Others recommend in-office testing for the reasons of convenience and cost effectiveness. The absence of prescription opioids in urine specimens has ranged from $1.9 \%$ to $15 \%(37,44-46)$. Further, studies also showed an overall presence of illicit drugs in approximately $11 \%$ (37) and false-negatives of $50 \%$ for cocaine, $11 \%$ for marijuana, and $9.3 \%$ for amphetamines.

Consequently, this diagnostic accuracy study has been undertaken to evaluate the accuracy of point of care (POC) or in-office UDT (immunoassay) of chronic pain patients in a prospective analysis of LC/MS/MS.

\section{Methods}

The study was undertaken in an interventional pain management practice, a tertiary referral center, in the United States. The protocol was approved by the Institutional Review Board (IRB) of the Ambulatory Surgery Center and it has a clinical trial registration of NCT01052155. Appropriate precautions were taken to protect the privacy and identify of patients evaluated from this study in accordance with current Health Insurance Portability and Accountability Act (HIPAA) regulations. 
The protocol has been described in a previous publication (36). The study was performed utilizing the Standards for Reporting of Diagnostic Accuracy Studies (STARD) established for reporting guidelines for diagnostic accuracy studies to improve the quality of reporting (48-50).

\section{Objective}

The objective of this study was to compare results of UDT of immunoassay in-office testing (index test) with LC/MS/MS (reference test).

\section{Proposed Hypothesis}

It is proposed that there is no significant difference of clinical importance between POC drug testing (index test) and laboratory drug testing (reference test).

\section{Investigational Methodology}

The investigational methodology followed the STARD checklist (48). All specimens were tested with immunoassay (index test) and LC/MS/MS (reference test).

\section{Participants and Recruitment}

Consecutive series of patients presenting for interventional pain management were recruited in a prospective manner.

\section{Inclusion and Exclusion Criteria}

Consecutive patients in chronic pain management were included. There were no exclusion criteria.

\section{Test Methods}

The index test was the in-house POC office drug testing with immunoassay; the reference standard was LC/MS/MS.

The laboratory test (reference test) was performed by Millennium Laboratories, which holds certificates for moderate and high complexity testing.

\section{Screening Evaluation}

All consecutive patients participating in the urine drug assessments diagnostic accuracy study were provided with a verbal explanation of the study. IRB-approved written informed consent to participate in the study was obtained.

Demographic details including date of birth, sex, weight, height, and drug profiles (which included a list of all prescription and over-the-counter drugs, as well as all other drugs or substances they were taking) were obtained.

\section{Treatment Number Assignment}

Participants were consecutively assigned a number.

\section{Urine Sample}

Urine and all other appropriate information were collected by a nurse participating in the study and provided to the study coordinator. POC testing was performed by a different nurse who was unaware of the patient's name, drug intake, etc. Drug testing was performed for opioids and illicit drugs including marijuana, cocaine, amphetamine, and methamphetamine.

\section{Laboratory Assessment}

After immunoassay, the samples were sent to laboratory for LC/MS/MS without any identifying information or results of the index text.

\section{Definition and Rationale}

The definition and rationale for the units, cutoffs, and categories of the results of the index test and how reference standard have been described (36).

\section{Personnel}

A sufficient number of nurses (6) received training to conduct and read the index test. The reference test was conducted by trained certified professionals at the laboratory.

\section{Blinding}

The personnel performing and reading the index tests and reference tests were blinded (masked) to the results of the other tests as well as patient demographics.

\section{Statistical Methods}

\section{Sample Size}

Sample size calculation was carried out for our primary outcome (accuracy of the POC drug testing in screening for opioids and illicit drugs) according to the previously published method (51), and previous results of drug abuse and illicit drug use by patients referred to clinics $(31-33,52)$. The details are provided in the protocol (36). The sample size was calculated at 811 with a planned enrollment of 1,000 patients to be tested.

\section{Analysis}

Statistical analysis was performed using SPSS 9.01 (SPSS, Inc., Chicago IL, USA). A P value below 0.05 was considered statistically significant. 
Results of the index test were compared to the reference test in all patients. The sensitivity, specificity, false-positive and false-negative rates, and index test efficiency (agreement) were calculated.

\section{REsULTS}

\section{Flow Diagram}

Figures 1 and 2 illustrate the patient flow diagram per STARD for opioids and illicit drugs.

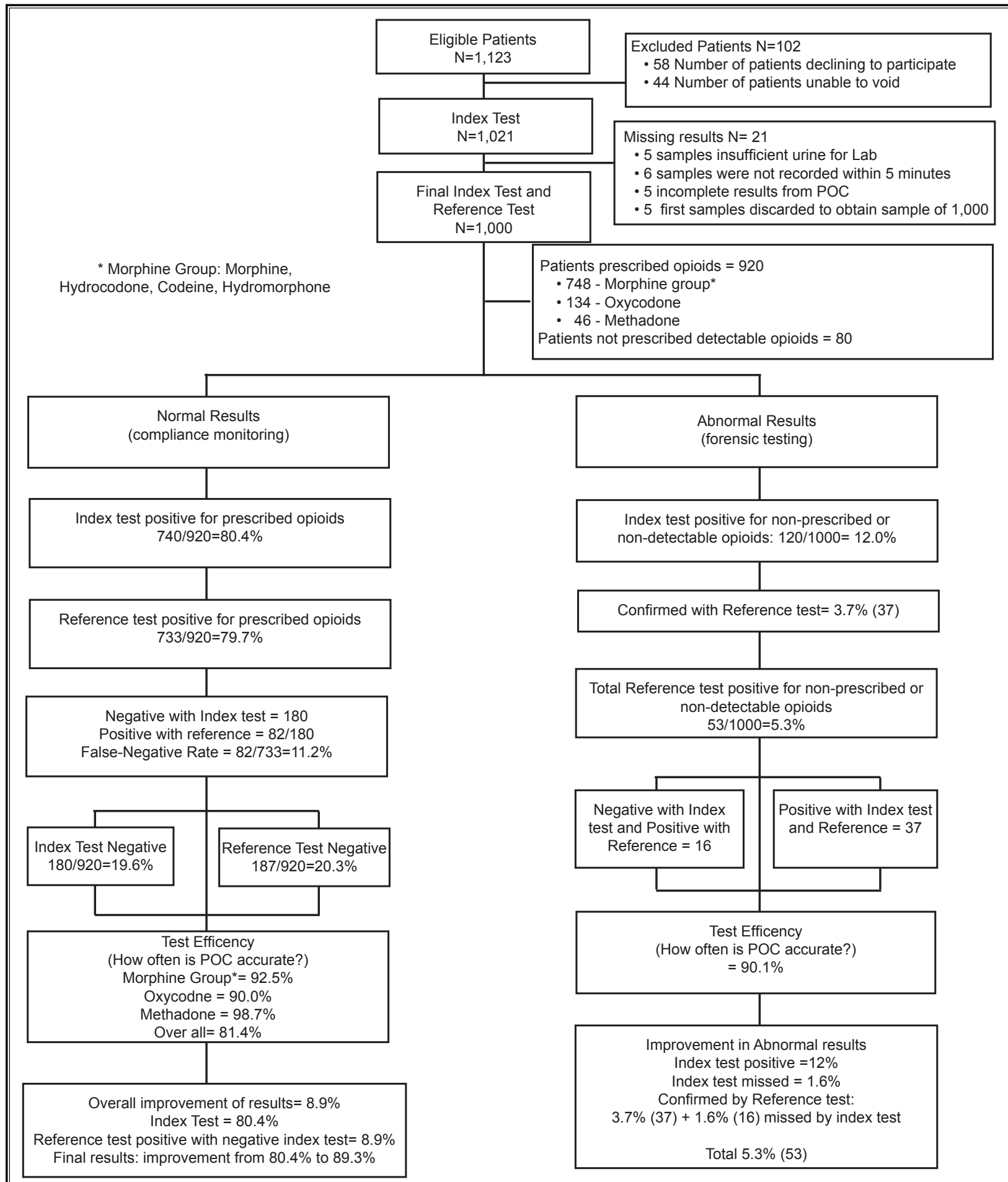

Fig. 1. Flow diagram of diagnostic accuracy testing of opioids. 


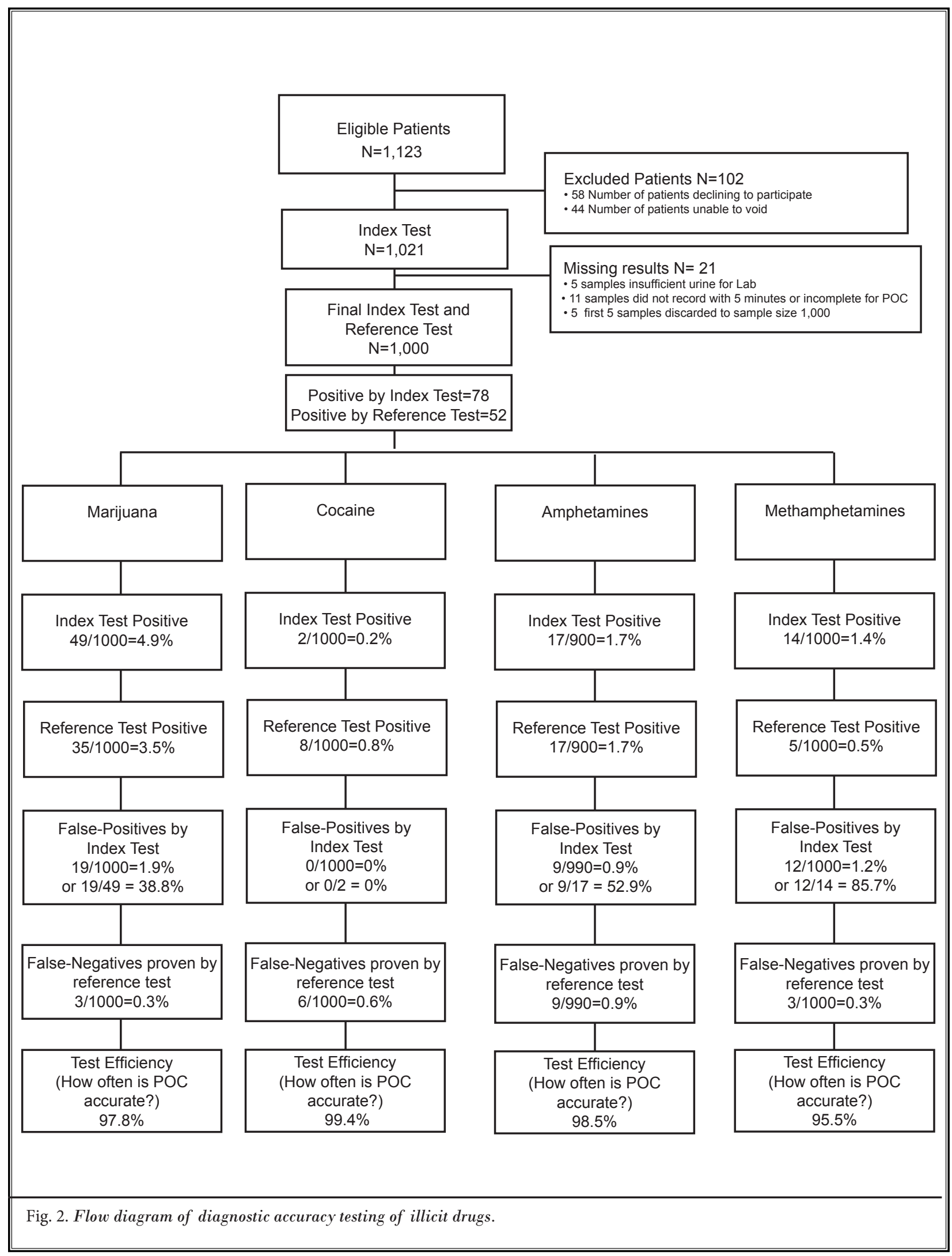




\section{Participants}

The study lasted from March 1, 2010, through June 30, 2010, with enrollment of consecutive patients. Evaluation days were selected by computerized randomization.

\section{Demographic Characteristics}

The demographic characteristics of the study population are illustrated in Table 1.

\section{Validity and Test Reproducibility}

One hundred specimens without identification or demographic data were tested for validity of the reference test. This showed perfect correlation.

\section{Numbers Analyzed}

The numbers analyzed are illustrated in Figures 1 and 2.

\section{Time Intervals}

The index test and reference test were performed on the same sample. The time interval for transporting the sample to the lab and performance of the test is estimated to have been about 72 hours.

\section{Distribution Characteristics}

The distribution of severity of disease is not applicable.

\section{Cross Tabulation of the Results}

A cross tabulation of the results of the index test and the reference test were performed.

Table 1. Demographic characteristics.

\begin{tabular}{||l|l|l||}
\hline \multirow{3}{*}{ Gender } & & Number \\
\hline \multirow{3}{*}{ Age (Years) } & Male & $37 \%(370)$ \\
\cline { 2 - 3 } & Female & $63 \%(630)$ \\
\hline Height & Mean \pm SD & $51 \pm 12.6$ \\
\hline Weight & & $66.5 \pm 4.2$ \\
\hline \multirow{3}{*}{ Insurance } & & $184.1 \pm 51.5$ \\
\hline \multirow{3}{*}{ State } & Medicare & $47.0 \%(470)$ \\
\cline { 2 - 3 } & Medicaid & $25.2 \%(252)$ \\
\cline { 2 - 3 } & Third Party & $27.8 \%(278)$ \\
\cline { 2 - 3 } & & \\
\cline { 2 - 3 } & & $82.9 \%(829)$ \\
\hline \hline
\end{tabular}

\section{Adverse Events}

No adverse events occurred while performing the index test or reference test.

\section{Estimates}

The estimated diagnostic accuracy and comparison were evaluated for all patients for each opioid prescribed and for illicit drugs.

\section{Results of Accuracy of Opioids and Illicit Drugs}

A summary of the diagnostic accuracy of the index test versus the reference test is illustrated in Table 2 . This table illustrates the cut-off levels utilized along with sensitivity, specificity, and agreement. For opioids with morphine, hydrocodone, codeine, and hydromorphone, there was $92.5 \%$ agreement with sensitivity of $92.2 \%$ and specificity of $93.0 \%$, with a false-negative rate of $7.8 \%$ and false-positive rate of $6.9 \%$. The numbers were better for methadone with sensitivity of $96.1 \%$ and specificity of $98.8 \%$ with an agreement of $98.7 \%$. However, for oxycodone sensitivity was $75.4 \%$ with false-negative rates of $24.6 \%$ and specificity of $92.3 \%$ with agreement of $90 \%$. For all illicit drugs, test agreement was high (approximately $98 \%$ or over). However, for cocaine sensitivity was $25 \%$ with falsenegative rates of $75 \%$ with specificity of $100 \%$. Methamphetamines and amphetamines also had lower sensitivity with $40 \%$ and $47 \%$. Consequently, these tests will show false-negative rates in $60 \%$ of the patients for methamphetamines and $53 \%$ for amphetamines even though specificity and agreement were high.

Table 3 illustrates a summary of the diagnostic accuracy of opioids with detailed data from the index test and the reference test. This table illustrates the same results as in Table 2 with detailed numbers.

\section{Discussion}

The results of this prospective, diagnostic accuracy study of UDT comparing in-office testing with immunoassay (index test) confirmed with laboratory testing of LC/MS/MS (reference test) showed significant agreement for opioids as well as illicit drugs. Specificity for opioids was $93.1 \%$ for the morphine group, $92.3 \%$ for oxycodone, and $98.8 \%$ for methadone. Sensitivity for opioids was $92.2 \%$ for the morphine group, $75.4 \%$ for oxycodone, and $96.1 \%$ for methadone. The agreement or test efficiency was $92.5 \%$ for the morphine group, $90 \%$ for oxycodone, and $98.7 \%$ for methadone. Similarly, for illicit drugs, specificity was $98 \%$ for marijuana, $100 \%$ for 
Table 2. Summary of diagnostic accuracy of opioids and illicit drugs (index test vs. reference test).

\begin{tabular}{|c|c|c|c|c|c|c|c|c|}
\hline & $\mathbf{T P}$ & FP & $\mathbf{T N}$ & FN & $\begin{array}{c}\text { Cutoff levels } \\
\text { (POC vs } \\
\text { LC/MS/MS) }\end{array}$ & $\begin{array}{c}\text { Sensitivity/ } \\
\text { False Negative } \\
\text { Rate }\end{array}$ & $\begin{array}{c}\text { Specificity/ } \\
\text { False Positive } \\
\text { Rate }\end{array}$ & $\begin{array}{c}\text { Test Efficiency } \\
\text { (Agreement) }\end{array}$ \\
\hline \multicolumn{9}{|l|}{ Opioids } \\
\hline $\begin{array}{l}\text { Morphine, Hydrocodone, } \\
\text { Codeine, Hydromorphone }\end{array}$ & 614 & 23 & 311 & 52 & $\begin{array}{c}300 \mathrm{ng} / \mathrm{mL} \\
\text { vs } 50 \mathrm{ng} / \mathrm{mL}\end{array}$ & $\begin{array}{c}92.2 \% / \\
7.8 \%\end{array}$ & $\begin{array}{c}93.1 \% / \\
6.9 \%\end{array}$ & $92.5 \%$ \\
\hline Oxycodone & 104 & 66 & 796 & 34 & $\begin{array}{c}100 \mathrm{ng} / \mathrm{mL} \\
\text { vs } 50 \mathrm{ng} / \mathrm{mL}\end{array}$ & $\begin{array}{l}75.4 \% / \\
24.6 \%\end{array}$ & $\begin{array}{l}92.3 \% / \\
7.7 \%\end{array}$ & $90.0 \%$ \\
\hline Methadone & 49 & 11 & 938 & 2 & $\begin{array}{c}300 \mathrm{ng} / \mathrm{mL} \\
\text { vs } 100 \mathrm{ng} / \mathrm{mL}\end{array}$ & $\begin{array}{c}96.1 \% / \\
3.9 \% \\
\end{array}$ & $\begin{array}{c}98.8 \% / \\
1.2 \% \\
\end{array}$ & $98.7 \%$ \\
\hline \multicolumn{9}{|l|}{ Illicit Drugs } \\
\hline Marijuana & 30 & 19 & 948 & 3 & $\begin{array}{c}50 \mathrm{ng} / \mathrm{mL} \\
\text { vs } 15 \mathrm{ng} / \mathrm{mL}\end{array}$ & $\begin{array}{l}90.9 \% / \\
9.1 \%\end{array}$ & $\begin{array}{l}98.0 \% / \\
2.0 \%\end{array}$ & $97.8 \%$ \\
\hline Cocaine & 2 & 0 & 992 & 6 & $\begin{array}{c}300 \mathrm{ng} / \mathrm{mL} \\
\text { vs } 50 \mathrm{ng} / \mathrm{mL}\end{array}$ & $\begin{array}{c}25.0 \% / \\
75 \%\end{array}$ & $\begin{array}{c}100.0 \% / \\
0 \%\end{array}$ & $99.4 \%$ \\
\hline Methamphetamines & 2 & 12 & 983 & 3 & $\begin{array}{c}\mathrm{NA} \\
50 \mathrm{ng} / \mathrm{mL}\end{array}$ & $\begin{array}{c}40.0 \% / \\
60 \%\end{array}$ & $\begin{array}{c}98.8 \% / \\
1.2 \%\end{array}$ & $98.5 \%$ \\
\hline Amphetamines ${ }^{\star}$ & 8 & 9 & 964 & 9 & $\begin{array}{r}1000 \mathrm{ng} / \mathrm{mL} \\
\text { vs } 100 \mathrm{ng} / \mathrm{mL}\end{array}$ & $\begin{array}{l}47.0 \% / \\
53.0 \%\end{array}$ & $\begin{array}{c}99.1 \% / \\
0.9 \%\end{array}$ & $98.2 \%$ \\
\hline
\end{tabular}

${ }^{*} \mathrm{n}=990$

$\mathrm{TP}=$ true positive; $\mathrm{TN}=$ true negative; $\mathrm{FP}=$ false-positive; $\mathrm{FN}=$ false-negative; $\mathrm{LC} / \mathrm{MS} / \mathrm{MS}=$ liquid chromatography-tandem mass spectrometry; $\mathrm{POC}=$ point of care; $\mathrm{NA}=$ not applicable

Table 3. Illustration of summary of diagnostic accuracy of opioids (index test vs. reference test).

\begin{tabular}{|c|c|c|c|c|c|c|c|c|c|c|c|c|c|}
\hline & & \multirow{2}{*}{\multicolumn{3}{|c|}{$\begin{array}{c}\text { Patients Prescribed } \\
\text { Morphine, Hydrocodone, } \\
\text { Codeine, Hydromorphone } \\
\text { group (748) } \\
\text { Reference Test } \\
\text { (LC/MS/MS) }\end{array}$}} & \multicolumn{3}{|c|}{$\begin{array}{c}\text { Patients Prescribed } \\
\text { Oxycodone } \\
(\mathbf{1 3 4})\end{array}$} & \multicolumn{3}{|c|}{$\begin{array}{c}\text { Patients Prescribed } \\
\text { Methadone } \\
(46)\end{array}$} & \multicolumn{3}{|c|}{$\begin{array}{c}\text { Patients with non- } \\
\text { prescribed opioids or no } \\
\text { prescribed opioids } \\
(1000)\end{array}$} \\
\hline & & & & & $\begin{array}{r}\operatorname{Re} \\
(\mathbf{I}\end{array}$ & $\begin{array}{l}\text { erence Te } \\
\text { C/MS/MS }\end{array}$ & & & $\begin{array}{l}\text { erence Te } \\
\text { C/MS/MS }\end{array}$ & & & $\begin{array}{l}\text { ference Te } \\
\text { C/MS/MS }\end{array}$ & \\
\hline & & Positive & Negative & Totals & Positive & Negative & Totals & Positive & Negative & Totals & Positive & Negative & Totals \\
\hline \multirow{3}{*}{$\begin{array}{c}\text { Index } \\
\text { Test } \\
\text { (POC) }\end{array}$} & Positive & 594 & 11 & 605 & 92 & 3 & 95 & 44 & 0 & 44 & 37 & 83 & 120 \\
\hline & Negative & 48 & 95 & 143 & 23 & 16 & 39 & 1 & 1 & 2 & 16 & 864 & 880 \\
\hline & Totals & 642 & 106 & 748 & 115 & 19 & 134 & 45 & 1 & 46 & 53 & 947 & 1000 \\
\hline \multicolumn{2}{|c|}{$\begin{array}{l}\text { Test Efficiency } \\
\text { (Agreement) }\end{array}$} & \multicolumn{3}{|c|}{$92.1 \%$} & \multicolumn{3}{|c|}{$80.6 \%$} & \multicolumn{3}{|c|}{$97.8 \%$} & \multicolumn{3}{|c|}{$90.1 \%$} \\
\hline \multicolumn{2}{|c|}{ Sensitivity } & \multicolumn{3}{|c|}{$92.5 \%(90 \%-94 \%)$} & \multicolumn{3}{|c|}{$80.0 \%(71 \%-87 \%)$} & \multicolumn{3}{|c|}{$97.8 \%(88 \%-99 \%)$} & \multicolumn{3}{|c|}{$69.8 \%(55 \%-82 \%)$} \\
\hline \multicolumn{2}{|c|}{ Specificity } & \multicolumn{3}{|c|}{$89.6 \%(82 \%-95 \%)$} & \multicolumn{3}{|c|}{$84.2 \%(60 \%-96 \%)$} & \multicolumn{3}{|c|}{$100(2 \%-100 \%)$} & \multicolumn{3}{|c|}{$93 \%(89 \%-93 \%)$} \\
\hline
\end{tabular}

LC/MS/MS=liquid chromatography-tandem mass spectrometry; POC=point of care

cocaine, $98.8 \%$ for methamphetamine, and $99.1 \%$ for amphetamine. However, the sensitivity was only $25 \%$ for cocaine, $40 \%$ for methamphetamine, $47 \%$ for amphetamine, and $90.9 \%$ for marijuana. One reason for such low sensitivity for illicit drugs is low prevalence rates. Thus, a larger sample size is needed to detect sensitivity. The agreement, or test specificity, for all illicit drugs was $95 \%$, with $97.8 \%$ for marijuana, $99.4 \%$ for cocaine, $98.5 \%$ for methamphetamine, and $98.2 \%$ for amphetamine. 
Multiple methodological issues are present in UDT, with immunoassays being based on the principle of competitive binding, detecting a particular drug group in a urine sample. In contrast, laboratory-based specific drug identification is sophisticated, but also more expensive. Thus, laboratory-based specific drug identification is needed to confirm the presence of a given drug and/or to identify drugs that cannot be isolated by a screening test. In addition, the cutoff levels for various drugs detected by urine analysis are also different between immunoassay testing and LC/MS/MS. Consequently, the capability of a particular immunoassay to detect drugs can vary according to both the drug concentration in the urine and the assessed cutoff concentration - with drug levels above cutoff being deemed to be positive. However, almost all immunoassays are subject to cross-reactivity. Some tests are highly predictive (i.e., cocaine, morphine, codeine), whereas others are very poorly predictive (i.e., amphetamine, methamphetamines, oxycodone) based on various other substances being ingested.

Previous studies performed in a prospective manner (31-33) showed the prevalence of illicit drug use to vary from $4.8 \%$ to $6.25 \%$ for cocaine, $11 \%$ to $18 \%$ for marijuana, and $2 \%$ to $3 \%$ for amphetamines and/or methamphetamine. Other studies, though not prospective and not diagnostic accuracy studies $(37,44,46,47)$, showed false-negative rates for oxycodone, hydrocodone, methadone, and other opioids variable from $1.9 \%$ to $15 \%(37,44,46)$ and false-negative rates for illicit drugs which were not detected in $9 \%$ to $50 \%$ of patients. Further, Gilbert et al (41), in attempting to reverse CMS regulation, showed that urine drug testing represented only approximately $18.2 \%$ of professional medical services rendered in 2007, a figure considered extremely high by others $(38,39)$. POC testing results examined in the present evaluation show an overall positive rate of $7.8 \% ; 0.2 \%$ for cocaine, $4.9 \%$ for marijuana, $1.7 \%$ for amphetamines, and $1.4 \%$ for methamphetamines. These results differ with previous studies. Further, false-negatives were observed in $75 \%$ for cocaine, $9.1 \%$, for marijuana, 53\% for amphetamines, and $60 \%$ for methamphetamines.

The results of the present study illustrated similar results for patients with prescribed opioids, with a false-negative rate of $19.6 \%$ for the index test and $20.3 \%$ for the reference test. The improved diagnostic accuracy with the reference test is $8.9 \%$, rising from $80.4 \%$ to $89.3 \%$; all the samples which were tested to be negative by immunoassay were confirmed by LC/MS/
MS, with 82 of 180 patients testing positive. In reference to non-prescribed opioids, $12 \%$ tested positive with the index test, with that test missing in $1.6 \%$ of the patients. However, only 37 of 120 were confirmed with the reference test, with 83 of 120 patients or $44 \%$ with false-positive results for non-opioid use with the index test performed in the office. Thus, a total of 53 patients, or $5.3 \%$, were using non-prescribed opioids.

Multiple authors have described the utility and application of UDT in chronic pain management with opioids (31-33,36,52-54). Nafziger and Bertino (53) described that UDT, when used with an understanding of the principles of pharmacokinetics, pharmacodynamics, and pharmacogenetics of opioids, can be a useful tool in chronic pain management. Thus, clinicians must keep in mind the limitations, purpose, and value of UDT, and the inability to predict patient compliance with the drug dosages used in commercial algorithms. Pergolizzi et al (52), in a compliance survey, discussed various aspects of UDT for patients in opioid therapy including the validity of UDT with reference to index and reference tests and the implications for reimbursement. With reference to cost issues, Gilbert et al (41) discussed the cost-benefit considerations of UDT, and that testing of chronic pain patients is analogous to the federal work place drug testing program, methadone clinics, and other areas, which have shown a definite cost benefit for UDT in this complex population. It has been estimated that each UDT in the past has cost Medicare up to $\$ 220$ per physician office payment, and up to an additional $\$ 600$ for laboratory testing. Some physicians have stated that any patient treated with controlled substances, including stable patients, should be seen in an office every 4 weeks and be required to have a UDT $(40,41,55,56)$. This increased frequency obviously has had a negative impact on patients and payers, as seen by new CMS guidance on this testing (45). Gilbert et al's (41) illustration of $18.2 \%$ income, the Ameritox indictment, and change of CMS coding patterns, illustrates the economic incentives for UDT (43).

The question which needs to be answered is: How many POC testing samples need to be sent to the lab? Based on our evaluation, it appears that it should be all samples testing negative for prescribed (detectable) opioids (184 patients), positive for non-prescribed opioids (123 patients), and positive for illicit drugs (68 patients), totaling 329 patients after eliminating positive duplications. However, these can be reduced based on a patient's admission of abnormal use, and the clinic's policy for controlled substances and illicit drugs. The re- 
ductions could range from $20 \%$ to $60 \%$, with a repeat of the immunoassay test during the patient's next appointment or at random. A repeat test should be much less expensive compared to sending the test to a lab; generally $\$ 25$ versus as much as $\$ 600$. Thus, careful analysis can save substantial amounts of health care dollars, specifically when performed judiciously without repeating during each visit in patients who do test normally, and repeating their tests only once a year and then only repeating in patients who present with abnormal results. One UDT might be more expensive than providing 2 to 3 epidural injections. Routine excessive UDT could result in annual charges as high as $\$ 10,000$, which is more expensive than managing patients with common opioids or appropriately performed therapeutic interventional techniques. However, multiple interventional techniques also have been criticized for escalating use, abuse, and lack of effectiveness (38,39,57-66). Based on cost-effectiveness, numerous guidelines have been developed, which are curbing chronic pain management therapy in the era of increasing pain, including interventional techniques and surgery based on evidence-based medicine and comparative effectiveness research $(34,38,39,67-99)$. Thus, appropriate use of immunoassay will be cost-effective with provision of appropriate care.

The present study can be criticized for limitations, which include a single site study utilizing a single POC kit and a single laboratory, as well as technical sponsorship. A multicenter study could be performed utilizing various manufacturers and different kits, etc.; however, this might provide irregular results. Consequently, as an initial diagnostic accuracy study, the present study is appropriate. Millennium Laboratories provided urine drug kits, laboratory evaluation at no cost, and expenses for employees for collecting the samples, transporting them, data entry, and analysis. However, They had no influence or interference after the protocol was designed. Further, the authors of the manuscript received no remuneration. Thus, we believe the results are valid.

Further, the results of this study illustrate practice patterns in an interventional pain management practice, rather than results generalizable to either all interventional pain medicine settings or primary care settings.

\section{Conclusion}

UDT with immunoassay in an office setting is an appropriate, convenient, and cost-effective test providing rapid results for evaluating opioid compliance. Compared with laboratory testing (LC/MS/MS) for opi- oids and illicit drugs, immunoassay in-office testing had high specificity and agreement, but variable sensitivity, demonstrating the value of immunoassay drug testing.

However, in patients with abnormal results, either by detection of non-prescribed opioid or illicit drugs, the results are not dependable and might have to be confirmed either by a repeat test, proper history, or confirmation by LC/MS/MS. Based on this evaluation, it appears that overall, as many as $32.9 \%$ or as few as $20 \%$ of patients could require their samples be sent for LC/MS/MS confirmation and subsequent patient management.

\section{Acknowledgments}

Author Contributions: Dr. Manchikanti had full access to all the data in the study and takes responsibility for the integrity of the data and the accuracy of the data analysis. Drs. Manchikanti, Malla, and Wargo designed the study protocol. Dr. Manchikanti managed the literature searches and summaries of previous related work and wrote the first draft of the manuscript. All other authors provided revision for intellectual content and final approval of the manuscript.

Conflict of Interest Disclosures: All authors have no conflicts of interest to report. None of the authors of the manuscript received any remuneration. Further, the authors have not received any reimbursement or honorarium in any other manner. The authors are not affiliated in any manner with Millennium Laboratories. However, all the authors are members of the American Society of Interventional Pain Physicians (ASIPP) and practicing interventional pain physicians except for Bert Fellows, who is a retired psychologist. Dr. Manchikanti is the Chairman of the Board and founder of ASIPP, which was responsible for the National All Schedules Prescription Electronic Reporting Act (NASPER) legislation and its implementation. Vidyasagar Pampati, MSc, statistician, is an employee of Ambulatory Surgery Center.

Funding/Support: The authors wish to disclose and thank the sponsor of the study. The study was conducted by the Pain Management Center of Paducah and the Ambulatory Surgery Center. The study was sponsored by Millennium Laboratories, 16981 Via Tazon, Suite F, San Diego, CA 92127. The sponsorship was limited to supplies and expenses. The sponsorship included payment for employees for collecting the samples, transportation of the specimens, data entry, and analysis of the data. They also provided urine drug kits and laboratory evaluation at no cost. They had no influence or interference after the protocol was designed. Their sponsorship of Florida Society of Interventional Pain 
Physicians, a state organization, has no relevance to the study and none of the Florida members were involved in conduct of the study.

Role of Sponsor: The financial sponsor of this work had no role in the design and conduct of the study or the collection, management, analysis, and interpretation of the data. The sponsor also did not have a role in the preparation or review of the manuscript or the decision to submit.
The authors also wish to thank Kimberly Cash, RT, research coordinator, Tom Prigge, MA for manuscript review, and Tonie M. Hatton and Diane E. Neihoff, transcriptionists, for their assistance in preparation of this manuscript. We would like to thank Vidyasagar Pampati, MSc, who was in charge of data entry storage and analysis. We also would like to thank the editorial board of Pain Physician for review and criticism in improving the manuscript.

\section{References}

1. Manchikanti L, Fellows B, Ailinani $\mathrm{H}$, Pampati V. Therapeutic use, abuse, and nonmedical use of opioids: A tenyear perspective. Pain Physician 2010; 13:401-435.

2. Wang J, Christo PJ. The influence of prescription monitoring programs on chronic pain management. Pain Physician 2009; 12:507-515.

3. Hernandez SH, Nelson LS. Prescription drug abuse: Insight into the epidemic. Clin Pharmacol Ther 2010; 88:307-317.

4. Braden JB, Russo J, Fan MY, Edlund MJ, Martin BC, DeVries A, Sullivan MD. Emergency department visits among recipients of chronic opioid therapy. Arch Intern Med 2010; 170:1425-1432.

5. Okie S. A flood of opioids, a rising tide of deaths. New Engl J Med 2010; 363:1981-1985.

6. Kuehn BM. Opioid prescriptions soar: Increase in legitimate use as well as abuse. JAMA 2007; 297:249-251.

7. Kuehn BM. Safety plan for opioids meets resistance: Opioid-linked deaths. JAMA 2010; 303:495-497.

8. Mularski RA, White-Chu F, Overbay D, Miller L, Asch SM, Ganzini L. Measuring pain as the 5 th vital sign does not improve quality of pain management. J Gen Intern Med 2006; 21:607-612.

9. Sjøgren P, Grønbæk M, Peuckmann V, Ekholm O. A population-based cohort study on chronic pain: the role of opioids. Clin J Pain 2010; 26:763-769.

10. Califano JA. High Society: How Substance Abuse Ravages America and What to Do About It. New York, Perseus Publishing, 2007.

11. United Nations Office on Drugs and Crime. 2007 World Drug Report.

12. Substance Abuse and Mental Health Services Administration. (2010). Results from the 2009 National Survey on
Drug Use and Health: Volume I. Summary of National Findings (Office of Applied Studies, NSDUH Series H-38A, HHS Publication No. SMA 10-4586Findings). Rockville, MD.

www.oas.samhsa.gov/NSDUH/ 2kgNSDUH/2kgResultsP.pdf.

13. Substance Abuse and Mental Health Services Administration, Office of Applied Studies. Drug Abuse Warning Network, 2007: National Estimates of Drug-Related Emergency Department Visits. Rockville, MD, 2010.

dawninfo.samhsa.gov/files/ED2007/ DAWN2k7ED.pdf

14. Warner M, Chen LJ, Makuc DM. Increase in fatal poisonings involving opioid analgesics in the United States, 1999-2006. NCHS data brief, no 22. Hyattsville, MD: National Center for Health Statistics, 2009.

15. Paulozzi LJ, Logan JE, Hall AJ, McKinstry E, Kaplan JA, Crosby AE. A comparison of drug overdose deaths involving methadone and other opioid analgesics in West Virginia. Addiction 2009; 104:1541-1548.

16. Fingerhut LA. Increases in poisoning and methadone-related deaths: United States, 1999-2005. Health E-Stats. National Center for Health Statistics; February 2008.

www.cdc.gov/nchs/data/hestat/poisoning/poisoning.pdf

17. Hall AJ, Logan JE, Toblin RL, Kaplan JA, Kraner JC, Bixler D, Crosby AE, Paulozzi L). Patterns of abuse among unintentional pharmaceutical overdose fatalities. JAMA 2008; 300:2613-2620.

18. Sullivan MD, Edlund MJ, Fan MY, Devries A, Brennan Braden J, Martin BC. Trends in use of opioids for non-cancer pain conditions 2000-2005 in commercial and Medicaid insurance plans: The TROUP study. Pain 2008; 138:440-449.
19. Caudill-Slosberg MA, Schwartz LM, Woloshin S. Office visits and analgesic prescriptions for musculoskeletal pain in US: 1980 versus 2000. Pain 2004; 109:514-519.

20. Boudreau D, Von Korff M, Rutter CM, Saunders K, Ray GT, Sullivan MD, Campbell Cl, Merrill JO, Silverberg MJ, Banta-Green C, Weisner C. Trends in long-term opioid therapy for chronic non-cancer pain. Pharmacoepidemiol Drug Saf 2009; 18:1166-1175.

21. Webster BS, Verma SK, Gatchel RJ. Relationship between early opioid prescribing for acute occupational low back pain and disability duration, medical costs, subsequent surgery, and late opioid use. Spine (Phila Pa 1976) 2007; 32:2127-2132.

22. Dunn KM, Saunders KW, Rutter CM, Banta-Green CJ, Merrill JO, Sullivan MD, Weisner CM, Silverberg MJ, Campbell $\mathrm{Cl}$, Psaty BM, Von Korff M. Opioid prescriptions for chronic pain and overdose: a cohort study. Ann Intern Med 2010; 152:85-92.

23. Katz MH. Long-term opioid treatment of nonmalignant pain: A believer loses his faith. Arch Intern Med 2010; 170:14221424.

24. National Opioids Use Guideline Group (NOUGG). Canadian guidelines for safe and effective use of opioids for chronic non-cancer pain, Version 5.6. April 2010.

http://nationalpaincentre.mcmaster.ca/documents/opioid_guideline_ part_b_v5_6.pdf Accessed December 17, 2010.

25. Noble M, Treadwell JR, Tregear SJ, Coates VH, Wiffen PJ, Akafomo C, Schoelles KM. Long-term opioid management for chronic noncancer pain. Cochrane Database Syst Rev. 2010; 1: CDo06605.

26. Chou R, Huffman L. Use of Chronic Opi- 
oid Therapy in Chronic Noncancer Pain: Evidence Review. Glenview, IL, American Pain Society, 2009.

www.ampainsoc.org/pub/pdf/Opioid_ Final_Evidence_Report.pdf

27. Manchikanti L, Benyamin R, Datta S Vallejo R, Smith HS. Opioids in chronic non-cancer pain. Expert Rev Neurother 2010; 10:775-789.

28. Kidner CL, Mayer TG, Gatchel RJ. Higher opioid doses predict poorer functiona outcome in patients with chronic disabling occupational musculoskeletal disorders. J Bone Joint Surg Am 2009; 91:919-927.

29. Vogt MT, Kwoh CK, Cope DK, Osial TA, Culyba M, Starz TW. Analgesic usage for low back pain: Impact on health care costs and service use. Spine (Phila Pa 1976) 2005; 30:1075-1081.

30. Silverman SM. Opioid induced hyperalgesia: Clinical implications for the pain practitioner. Pain Physician 2009; 12:679-684.

31. Manchikanti L, Damron KS, Pampati V, McManus CD. Prevalence of illicit drug use among individuals with chronic pain in the Commonwealth of Kentucky: An evaluation of patterns and trends. J Ky Med Assoc 2005; 103:5562.

32. Manchikanti L, Manchukonda R, Damron KS, Brandon D, McManus CD, Cash $\mathrm{KA}$. Does adherence monitoring reduce controlled substance abuse in chronic pain patients? Pain Physician 2006; 9:57-60.

33. Manchikanti L, Pampati V, Damron KS, Beyer CD, Barnhill RC, Fellows B. Prevalence of prescription drug abuse and dependency in patients with chronic pain in western Kentucky. J Ky Med AsSOC 2003; 101:511-517.

34. Manchikanti L, Singh V, Datta S, Cohen SP, Hirsch JA. Comprehensive review of epidemiology, scope, and impact of spinal pain. Pain Physician 2009; 12: E35-E70.

35. Freburger JK, Holmes GM, Agans RP, Jackman AM, Darter JD, Wallace AS, Castel LD, Kalsbeek WD, Carey TS. The rising prevalence of chronic low back pain. Arch Intern Med 2009; 169:251258.

36. Manchikanti L, Malla Y, Wargo BW, Cash KA, Pampati V, Damron KS, McManus $\mathrm{CD}$, Brandon DE. Protocol for accuracy of point of care (POC) or in-office urine drug testing (immunoassay) in chronic pain patients: A prospective analysis of immunoassay and liquid chromatography tandem mass spectometry (LC/ MS/MS). Pain Physician 2010; 13:E1E22.

37. Couto JE, Romney MC, Leider HL, Sharma S, Goldfarb NI. High rates of inappropriate drug use in the chronic pain population. Popul Health Manage 2009; 12:185-190.

38. Manchikanti L, Singh V, Boswell MV. Interventional pain management at crossroads: The perfect storm brewing for a new decade of challenges. Pain Physician 2010; 13: E111-E140.

39. Benyamin RM, Datta S, Falco FJE. A perfect storm in interventional pain management: Regulated, but unbalanced. Pain Physician 2010; 13:109-116.

40. Gilbert JW, Wheeler GR, Mick GE, Storey $\mathrm{BB}$, Herder $\mathrm{SL}$, Richardson GB, Watts E, Gyarteng-Dakwa K, Marino BS, Kenney CM, Siddiqi M, Broughton PG. Importance of urine drug testing in the treatment of chronic non-cancer pain: Implications of recent medicare policy changes in Kentucky. Pain Physician 2010; 13:167-186.

41. Gilbert JW, Wheeler GR, Mick GE, Storey BB, Herder SL, Richardson GB, Watts E, Gyarteng-Dakwa K, Marino BS, Kenney CM, Siddiqi M, Broughton PG. Urine drug testing in the treatment of chronic noncancer pain in a Kentucky private neuroscience practice: the potential effect of Medicare benefit changes in Kentucky. Pain Physician 2010; 13:187194.

42. Dobson A, Heath S, El-Gamil A, DaVanzo JE. Assessing potential Medicare savings from implementing a change in payment for selected clinical laboratory services. July 10, 2009.

www.dobsondavanzo.com/clientuploads/publications/Dominion_Diagnostics-Final_Draft7.10.09_v3.pdf

43. Ameritox Ltd., agrees to pay $\$ 16.3$ million to resolve kickback claims associated with laboratory testing services [press release]. United States Attorney's Office, Middle District of Florida; November 16, 2010.

www.justice.gov/usao/flm/pr/2010/ nov/20101116_\%20Civil\%20Ameritox. pdf

44. Pesce A, Rosenthal M, West R, West C, Mikel C, Almazan P, Latyshev S. An evaluation of the diagnostic accuracy of liquid chromatography-tandem mass spectrometry versus immunoas say drug testing in pain patients. Pain
Physician 2010; 13:273-281.

45. CMS Manual System. Pub 100-04 Medicare claims processing, Transmittal 1884, Change Request 6657. Calendar Year (CY) 2010 Annual Update for Clinical Laboratory Fee Schedule and Laboratory Services Subject to Reasonable Charge Payment. December 23, 2009. WWW.cms.gov/transmittals/downloads/R1884CP.pdf

46. West R, Pesce A, West C, Crews B, Mikel C, Rosenthal M, Almazan P, Latyshev S. Observations of medication compliance by measurement of urinary drug concentrations in a pain management population. J Opioid Manage 2010; 6:253-257.

47. Pesce A, West C, Rosenthal M, West R, Crews B, Mikel C, Almazan P, Latyshev $S$, Horn PS. Marijuana correlates with use of other illicit drugs in a pain patient population. Pain Physician 2010; 13:283-287.

48. Bossuyt PM, Reitsma JB, Bruns DE, Gatsonis CA, Glasziou PP, Irwig LM, Lijmer JG, Moher D, Rennie D, de Vet HC; Standards for Reporting of Diagnostic Accuracy. Towards complete and accurate reporting of studies of diagnostic accuracy: The STARD initiative. Clin Chem 2003; 49:1-6.

49. Manchikanti L, Derby R, Wolfer LR, Singh V, Datta S, Hirsch JA. Evidencebased medicine, systematic reviews, and guidelines in interventional pain management: Part 5. Diagnostic accuracy studies. Pain Physician 2009; 12:517-540.

50. Manchikanti L, Derby R, Wolfer LR, Singh V, Datta S, Hirsch JA. Evidencebased medicine, systematic reviews, and guidelines in interventional pain management: Part 7: Systematic reviews and meta-analyses of diagnostic accuracy studies. Pain Physician 2009; 12:929-963.

51. Jones SR, Carley S, Harrison M. An introduction to power and sample size estimation. Emerg Med J 2003; 20:453458.

52. Pergolizzi J, Pappagallo M, Stauffer J, Gharibo C, Fortner N, De Jesus MN, Brennan MJ, Richmond C, Hussey D; Integrated Drug Compliance Study Group (IDCSG). The role of urine drug testing for patients on opioid therapy. Pain Pract 2010; 10:497-507.

53. Nafziger AN, Bertino JS. Utility and application of urine drug testing in chronic pain management with opioids. Clin J 
Pain 2009; 25:73-79.

54. Bair MJ, Krebs EE. Why is urine drug testing not used more often in practice? Pain Pract 2010; 10:493-496.

55. Marcus D. Managing chronic pain in the primary care setting. 2002. w w wafp.org/ afp/20020701/editorials.html.

56. U.S. Department of Transportation. Procedures for transportation workplace drug and alcohol testing programs. 49 CFR Part 40. www.dot. gov/ost/dapc/NEW_DOCS/part40. html.

57. Manchikanti L, Singh V, Pampati V, Smith HS, Hirsch JA. Analysis of growth of interventional techniques in managing chronic pain in Medicare population: A 10-year evaluation from 1997 to 2006. Pain Physician 2009; 12:9-34.

58. Manchikanti L, Pampati V, Singh V, Boswell MV, Smith HS, Hirsch JA. Explosive growth of facet joint interventions in the Medicare population in the United States: A comparative evaluation of 1997, 2002, and 2006 data. BMC Health Serv Res 2010; 10:84.

59. Manchikanti L, Pampati V, Boswell MV, Smith HS, Hirsch JA. Analysis of the growth of epidural injections and costs in the Medicare population: A comparative evaluation of 1997, 2002, and 2006 data. Pain Physician 2010; 13:199-212.

6o. Staal JB, de Bie RA, de Vet HC, Hildebrandt J, Nelemans P. Injection therapy for subacute and chronic low back pain: An updated Cochrane review. Spine (Phila Pa 1976) 2009; 34:49-59.

61. Chou R, Huffman L. Guideline for the Evaluation and Management of Low Back Pain: Evidence Review. Glenview, IL, American Pain Society, 2009.

www.ampainsoc.org/pub/pdf/LBPEvidRev.pdf

62. Manchikanti L, Falco FJE, Boswell MV, Hirsch JA. Facts, fallacies, and politics of comparative effectiveness research: Part 1. Basic considerations. Pain Physician 2010; 13:E23-E54.

63. Manchikanti L, Falco FJE, Boswell MV, Hirsch JA. Facts, fallacies, and politics of comparative effectiveness research: Part 2. Implications for interventional pain management. Pain Physician 2010; 13:E55-E79.

64. Manchikanti L, Datta S, Derby R, Wolfer LR, Benyamin RM, Hirsch JA. A critical review of the American Pain Society clinical practice guidelines for interventional techniques: Part 1. Diagnostic in- terventions. Pain Physician 2010; 13: E141-E174.

65. Manchikanti L, Datta S, Gupta S, Mung lani R, Bryce DA, Ward SP, Benyamin RM, Sharma ML, Helm II S, Fellows B, Hirsch JA. A critical review of the American Pain Society clinical practice guidelines for interventional techniques: Part 2. Therapeutic interventions. Pain Physician 2010; 13:E215-E264.

66. Deyo RA, Mirza SK, Martin BI, Kreuter W, Goodman DC, Jarvik JG. Trends, major medical complications, and charges associated with surgery for lumbar spinal stenosis in older adults. JAMA 2010; 303:1259-1265.

67. Manchikanti L, Boswell MV, Singh V, Benyamin RM, Fellows B, Abdi S, Buenaventura RM, Conn A, Datta S, Derby R, Falco FJE, Erhart S, Diwan S, Hayek SM, Helm S, Parr AT, Schultz DM, Smith HS, Wolfer LR, Hirsch JA. Comprehensive evidence-based guidelines for interventional techniques in the management of chronic spinal pain. Pain Physician 2009; 12:699-802.

68. Manchikanti L, Boswell MV, Singh V, Derby R, Fellows B, Falco FJE, Datta S, Smith HS, Hirsch JA. Comprehensive review of neurophysiologic basis and diagnostic interventions in managing chronic spinal pain. Pain Physician 2009; 12:E71-E120.

69. Manchikanti L, Boswell MV, Datta S, Fellows B, Abdi S, Singh V, Benyamin RM, Falco FJE, Helm S, Hayek S, Smith HS. Comprehensive review of therapeutic interventions in managing chronic spinal pain. Pain Physician 2009; 12:E123E198.

70. Manchikanti L, Helm S, Singh V, Benyamin RM, Datta S, Hayek S, Fellows B, Boswell MV. An algorithmic approach for clinical management of chronic spinal pain. Pain Physician 2009; 12:E225E264.

71. Falco FJE, Erhart S, Wargo BW, Bryce DA, Atluri S, Datta S, Hayek SM. Systematic review of diagnostic utility and therapeutic effectiveness of cervical facet joint interventions. Pain Physician 2009; 12:323-344.

72. Datta S, Lee M, Falco FJE, Bryce DA, Hayek SM. Systematic assessment of diagnostic accuracy and therapeutic utility of lumbar facet joint interventions. Pain Physician 2009; 12:437460.

73. Manchikanti L, Dunbar EE, Wargo BW, Shah RV, Derby R, Cohen SP. System- atic review of cervical discography as a diagnostic test for chronic spinal pain. Pain Physician 2009; 12:305-321.

74. Manchikanti L, Glaser S, Wolfer L, Derby $R$, Cohen SP. Systematic review of lumbar discography as a diagnostic test for chronic low back pain. Pain Physician 2009; 12:541-559.

75. Conn A, Buenaventura R, Datta S, Abdi $S$, Diwan S. Systematic review of caudal epidural injections in the management of chronic low back pain. Pain Physician 2009; 12:109-135.

76. Parr AT, Diwan S, Abdi S. Lumbar interlaminar epidural injections in managing chronic low back and lower extremity pain: A systematic review. Pain Physician 2009; 12:163-188.

77. Benyamin RM, Singh V, Parr AT, Conn A, Diwan S, Abdi S. Systematic review of the effectiveness of cervical epidurals in the management of chronic neck pain. Pain Physician 2009; 12:137-157.

78. Buenaventura RM, Datta S, Abdi S, Smith HS. Systematic review of therapeutic lumbar transforaminal epidural steroid injections. Pain Physician 2009; 12:233-251.

79. Helm S, Hayek S, Benyamin RM, Manchikanti L. Systematic review of the effectiveness of thermal annular procedures in treating discogenic low back pain. Pain Physician 2009; 12:207-232.

8o. Frey ME, Manchikanti L, Benyamin RM, Schultz DM, Smith HS, Cohen SP. Spinal cord stimulation for patients with failed back surgery syndrome: A systematic review. Pain Physician 2009; 12:379-397.

81. Epter RS, Helm S, Hayek SM, Benyamin RM, Smith HS, Abdi S. Systematic review of percutaneous adhesiolysis and management of chronic low back pain in post lumbar surgery syndrome. Pain Physician 2009; 12:361-378.

82. Patel VB, Manchikanti L, Singh V, Schultz DM, Hayek SM, Smith HS. Systematic review of intrathecal infusion systems for long-term management of chronic non-cancer pain. Pain Physician 2009; 12:345-360.

83. Rupert MP, Lee M, Manchikanti L, Datta S, Cohen SP. Evaluation of sacroiliac joint interventions: A systematic appraisal of the literature. Pain Physician 2009; 12:399-418.

84. Hayek SM, Helm S, Benyamin RM, Singh V, Bryce DA, Smith HS. Effectiveness of spinal endoscopic adhesioly- 
sis in post lumbar surgery syndrome: A systematic review. Pain Physician 2009; 12:419-435.

85. Hirsch JA, Singh V, Falco FJE, Benyamin RM, Manchikanti L. Automated percutaneous lumbar discectomy for the contained herniated lumbar disc: A systematic assessment of evidence. Pain Physician 2009; 12:601-620.

86. Singh V, Manchikanti L, Benyamin RM, Helm S, Hirsch JA. Percutaneous lumbar laser disc decompression: A systematic review of current evidence. Pain Physician 2009; 12:573-588.

87. Singh V, Benyamin RM, Datta S, Falco FJE, Helm S, Manchikanti L. Systematic review of percutaneous lumbar mechanical disc decompression utilizing Dekompressor . Pain Physician 2009; 12:589-599.

88. Manchikanti L, Derby R, Benyamin RM, Helm S, Hirsch JA. A systematic review of mechanical lumbar disc decompression with nucleoplasty. Pain Physician 2009; 12:561-572.

89. Gerges FJ, Lipsitz SR, Nedeljkovic SS. A systematic review on the effectiveness of the nucleoplasty procedure for discogenic pain. Pain Physician 2010; 13:117-132.

90. Manchikanti L, Cash KA, McManus CD, Pampati V, Singh V, Benyamin RM. The preliminary results of a comparative effectiveness evaluation of adhesiolysis and caudal epidural injections in managing chronic low back pain second- ary to spinal stenosis: A randomized, equivalence controlled trial. Pain Physician 2009; 12:E341-E354.

91. Manchikanti L, Singh V, Cash KA, Pampati V, Datta S. A comparative effectiveness evaluation of percutaneous adhesiolysis and epidural steroid injections in managing lumbar post surgery syndrome: A randomized, equivalence controlled trial. Pain Physician 2009; 12:E355-E368.

92. Manchikanti L, Pampati V, Cash KA. Protocol for evaluation of the comparative effectiveness of percutaneous adhesiolysis and caudal epidural steroid injections in low back and/or lower extremity pain without post surgery syndrome or spinal stenosis. Pain Physician 2010; 13:E91-E110.

93. Manchikanti L, Singh V, Falco FJE, Cash KA, Pampati V. Evaluation of lumbar facet joint nerve blocks in managing chronic low back pain: A randomized, double-blind, controlled trial with a 2-year follow-up. Int J Med Sci 2010; 7:124-135.

94. Manchikanti L, Singh V, Falco FJE, Cash KA, Pampati V, Fellows B. Comparative effectiveness of a one-year followup of thoracic medial branch blocks in management of chronic thoracic pain: A randomized, double-blind active controlled trial. Pain Physician 2010; 13:535-548.

95. Manchikanti L, Singh V, Falco FJE, Cash KA, Fellows B. Comparative outcomes of a 2-year follow-up of cervical medial branch blocks in management of chronic neck pain: A randomized, double-blind controlled trial. Pain Physician 2010; 13:437-450.

96. Manchikanti L, Cash KA, McManus CD, Pampati V, Benyamin RM. A preliminary report of a randomized doubleblind, active controlled trial of fluoroscopic thoracic interlaminar epidural injections in managing chronic thoracic pain. Pain Physician 2010; 13:E357E369.

97. Manchikanti L, Singh V, Cash KA, Datta $S$. Management of pain of post lumbar surgery syndrome: One-year results of a randomized, double-blind, active controlled trial of fluoroscopic caudal epidural injections. Pain Physician 2010; 13:509-521.

98. Manchikanti L, Singh V, Falco FJE, Cash $K A$, Pampati V. Evaluation of the effectiveness of lumbar interlaminar epidural injections in managing chronic pain of lumbar disc herniation or radiculitis: A randomized, double-blind, controlled trial. Pain Physician 2010; 13:343-355.

99. Manchikanti L, Cash KA, Pampati V, Wargo BW, Malla Y. Cervical epidural injections in chronic discogenic neck pain without disc herniation or radiculitis: Preliminary results of a randomized, double-blind, controlled trial. Pain Physician 2010; 13:E265-E278. 
